\title{
LEGISLAÇÃO EDUCACIONAL E FORMAÇÃO DOCENTE PARA A EDUCAÇÃO DAS RELAÇÕES ÉTNICO-RACIAIS
}

\author{
EDUCATIONAL LEGISLATION AND TEACHER TRAINING \\ FOR THE EDUCATION OF ETHNIC-RACIAL RELATIONS
}

\author{
Leandra Aparecida Mendes dos Santos Rodrigues \\ Instituto Federal de Educação, Ciência e Tecnologia Goiano - Campus Urutaí \\ Leida Corrêa da Silva \\ Instituto de Educação, Ciência e Tecnologia Goiano - Campus Urutaí \\ Patrícia Gonçalves de Jesus \\ Instituto Federal de Educação, Ciência e Tecnologia Goiano - Campus Urutaí \\ Cristiane Maria Ribeiro \\ Instituto Federal de Educação, Ciência e Tecnologia Goiano - Campus Urutaí
}

\begin{abstract}
RESUMO:
O objetivo desta pesquisa foi identificar na legislação educacional brasileira, regulamentada após os anos de 1990 referências sobre a formação de professores e a Educação das Relações Étnico-Raciais (ERER).Tratase de uma pesquisa de levantamento bibliográfico e documental, visto que analisa leis e documentos oficiais, destacando as referências sobre a formação de professores para o trabalho com a ERER, bem como faz uma problematização fundamentada em bibliografias sobre a temática discutida. Dos 19 documentos incluídos na análise, dentre Leis, Pareceres, Resoluções, Portarias e Orientações, 6 destes documentos apresentam referências específicas para a formação de professores para a ERER; 4 apresentam referências para as questões étnico-raciais; 5 trazem referências para a formação inicial e continuada de professores e 4 não trazem referências sobre a formação de professores para a implementação da ERER e nem sobre as relações étnico-raciais. Percebeu-se que a legislação educacional traz referências e suporte para a implementação da ERER, porém esta legislação não se impõe por si própria, estando sujeita, em sua aplicação, à formação e capacitação dos professores.
\end{abstract}

Palavras-chaves: Formação de professores. Educação das Relações étnico-raciais. Legislação Educacional

\section{ABSTRACT:}

The objective of this research was to identify in Brazilian educational legislation, regulated after the 1990s references on teacher training and the Education of Ethnic-Racial Relations (ERER). This is a bibliographic and documentary survey research, seen which analyzes laws and official documents, highlighting references on the training of teachers to work with ERER, as well as problematizing them based on bibliographies on the topic discussed. Of the 19 documents included in the analysis, among Laws, Opinions, Resolutions, 
Ordinances and Guidelines, 6 of these documents present specific references for the training of teachers for ERER; 4 present references to ethnic-racial issues; 5 provide references for initial and continuing teacher training and 4 do not provide references on teacher training for the implementation of ERER or on ethnicracial relations. It was noticed that the educational legislation brings references and support for the implementation of ERER, however this legislation does not impose itself, being subject, in its application, to the training and qualification of teachers.

Keywords: Teacher training. Education of ethnic-racial relations. Educational Legislation 


\section{INTRODUÇÃO}

A sociedade brasileira é constituída na diversidade étnico-racial e cultural e estes elementos reverberam no chão da escola, neste contexto, se faz necessário uma reflexão sobre a garantia do acesso e permanência na educação para todos os sujeitos que compõem a sociedade brasileira, sendo pertinente, portanto, saber se os profissionais da educação estão capacitados para desenvolverem uma educação antirracista (CAVALLEIRO, 2001).

O objetivo desta pesquisa foi identificar na legislação educacional brasileira, regulamentada após os anos de 1990 referências sobre a formação de professores para trabalhar a Educação das Relações Étnico-Raciais (ERER).

Primeiramente, fez-se uma reflexão com base em pesquisadores sobre as políticas educacionais e formação de professores para o desenvolvimento da ERER. Segue-se analisando a legislação educacional, destacando as referências sobre a formação de professores para o trabalho com a ERER.

Considera-se que a formação de professores para trabalhar a ERER é imprescindível, pois, a instrumentalização dos profissionais que atuam é pré-requisito para identificar assimetrias nas relações dentro do contexto educacional e também para o planejamento e implementação de ações pedagógicas antirracistas.

Com base na literatura observou-se que um problema para a implementação da ERER encontra-se na formação inicial e continuada dos professores, uma vez que na análise documental percebeu-se que a legislação educacional traz referências e suporte para sua implementação.

\section{Políticas Públicas Educacionais}

Neste item faz-se uma reflexão sobre as políticas educacionais no contexto escolar, buscando destacar o poder de interferência que estas ações têm sobre a realidade da 
educação. A discussão da escola como espaço de formação e de socialização é uma temática recorrente entre pesquisadores da área da educação, pois além de conhecimentos sistematizados, esta instituição é um dos mais importantes centros de difusão da cultura humana e vista como a solução para os problemas de exclusão (SANTOS, 2019; SOUZA, 2009).

Segundo Demo a educação "é capaz de abrir um horizonte mais visível de oportunidades, como sobretudo é capaz de promover um sujeito apto a fazer-se oportunidade" (DEMO, 1998, p. 176). Para a melhoria do processo educativo e a instalação de uma educação de qualidade, Dourado e Oliveira (2009) ressaltam a importância da implantação e monitoramento de políticas educacionais e de seus resultados, visando produzir uma escola de qualidade socialmente referenciada.

As políticas públicas educacionais "podem ser representadas pelas leis, pelo planejamento, pelo financiamento e pelos programas educacionais que falam de um movimento/ação do Estado" (SANTOS, 2011, p.1). Estas políticas buscam contemplar a diversidade, ampliar as formas de ingresso a educação e preocupam-se com dispositivos que garantam a permanência na escola (OLIVEIRA, 2014).

As políticas de caráter compensatório objetivam reparar dívidas históricas com segmentos sociais e apresentam estratégias de superação de uma condição de vulnerabilidade. As políticas compensatórias são destinadas a públicos específicos e objetivam articular o critério da diversidade combinado à desigualdade, são políticas de recuperação (ou superação) de uma condição de vulnerabilidade que precisa ser atacada (OLIVEIRA, 2014).

No Brasil, "as reformas educacionais ocorridas no final do século XX e que continuam sendo desenvolvidas no século XXI são resultados das transformações sofridas pelo capitalismo a nível mundial sob as orientações do paradigma neoliberal" (AZEVEDO; AZEVEDO, 2019, p. 1471). Desse modo, Azevedo e Azevedo (2019) discorrem que a escola passa a ser pautada em avaliações classificatórias por desempenho, currículos voltados às necessidades de formação para o mercado de trabalho, concepções gerencialistas na 
gestão das escolas, pois a configuração internacional do capitalismo trouxe impactos para a pedagogia e para a gestão das escolas.

Com a Lei de Diretrizes e Bases (LDB) de 1996 ocorreram mudanças nas responsabilidades dos entes federados quanto à manutenção e ao desenvolvimento do ensino. A LDB induz fortemente à descentralização da educação, ou seja, compreende-se delegação de funções para entidades regionais ou locais que dependem diretamente do Estado (SANTOS, 2011).

Desse modo o FUNDEF (Fundo de Manutenção e Desenvolvimento do Ensino Fundamental e da Valorização do Magistério) somada aos Parâmetros Curriculares Nacionais e à instituição do Sistema Nacional de Avaliação da Educação Básica (SAEB) mostram quais os direcionamentos do governo em relação à política educacional. Ou seja, a intenção é direcionar os gastos para o Ensino Fundamental como estratégia de preparação de mão-de-obra para o mercado de trabalho, de maneira que um certo tipo de controle fosse mantido pelo governo (SANTOS, 2011).

No cenário atual o debate é visível, tanto sobre as políticas educacionais, Reforma do Ensino Médio, BNCC, Diretrizes para Formação dos Professores, quanto em Programas do Governo para efetivar as políticas educacionais, tais como: Escolas Cívico Militares; Novos Caminhos e Future-se (ESQUINSANI; SOBRINHO, 2020). Mesmo com a ampliação das políticas educacionais das últimas décadas, muitos desafios são enfrentados pelo país para ampliar e qualificar a educação em todos os níveis, etapas e modalidades (OLIVEIRA, 2014).

Não se pode desvincular as desigualdades sociais das desigualdades educacionais, pois a primeira se reflete na segunda. Neste contexto, Oliveira (2011) destaca que existe um vínculo entre educação e desigualdade social, o que ocasiona consequências importantes para se pensar em estratégias políticas destinadas a enfrentar os problemas de desigualdade educacional.

Paro (2010) destaca que a educação não acontece dissociada do contexto histórico e social, pois é resultado de uma evolução histórica, a qual traz a marca das contradições 
sociais e dos interesses políticos determinantes na sociedade. Nesta perspectiva, o Brasil está organizado sob o sistema capitalista, em que a classe dominante se apropria da força de trabalho das classes dominadas. Esta dominação é consolidada através de estruturas jurídicas, políticas, sociais e culturais, o que influencia na realidade educacional do país (AZEVEDO; AZEVEDO, 2019).

Sendo assim “o Estado incute nos envolvidos no processo da escola a ideia de que são autônomas, mas na realidade não fazem mais do que reproduzir, de modo sutil e dissimulado, a lógica do capital” (DANTAS; FREITAS, 2020, p. 14).

Ressalta-se a importância da legislação educacional para garantir a igualdade de oportunidades de acesso e permanência e uma educação de qualidade. A legislação educacional determina princípios ao sistema educacional de um país por meio de diretrizes e normas. Estas orientações refletem na organização e no funcionamento das instituições responsáveis pela educação sistemática (SOUSA, 2009).

Desde o final da década de 1980 a legislação brasileira vem sendo alterada a fim de conferir maiores garantias em matéria educacional (OLIVEIRA, 2014). Começando pela Constituição Federal de 1988 que garante a educação para todos os cidadãos e traz no corpus do seu texto muitas reivindicações dos educadores como a gestão democrática, o financiamento da educação e a valorização profissional (SANTOS, 2011).

Diante de uma sociedade constituída na diversidade é que Santos afirma ser necessário investir desigualmente entre desiguais, ampliando as possibilidades dos mais vulneráveis para que superarem os condicionantes históricos que os fizeram vulneráveis (SANTOS, 2019).

O que é reforçado no Documento Referência da Conferência Nacional de Educação (CONAE 2014). Este documento faz uma síntese de propostas e anseios de distintos segmentos do campo educacional e expressa uma direção para a educação brasileira, afirmando que o " direito se realiza no contexto desafiador de superação das desigualdades e do reconhecimento e respeito à diversidade" (BRASIL, 2012, p. 59). 
A Educação é sinônimo de transformação, superação, emancipação, desse modo cabe à escola promover uma formação ética e social que faça os sujeitos compreenderem as leis e alcançarem a emancipação. Nesse sentido, ser emancipado é ser consciente de seus atos e das armadilhas que o Estado capitalista tenta ideologicamente incutir utilizando as políticas públicas para a manutenção da hegemonia e valorização da cultura dominante (DANTAS; FREITAS, 2020)

Portanto, as políticas educacionais ou políticas de ações afirmativas que garantem a ERER são de fundamental importância para o processo de valorização da diversidade no contexto escolar. Estas políticas são fundamentais para se garantir a população negra o acesso e a permanência na escola, usufruindo de uma educação de qualidade.

\section{A formação de professores e a ERER}

Propõe-se neste item a problematização sobre a formação de professores para a ERER, a partir da interpretação da sua institucionalidade presente nos marcos normativos destinados à educação.

Por meio da luta e reinvindicações feitas pelo Movimento Negro brasileiro contra o racismo foi promulgada a Lei $\mathrm{n}^{0} 10.639$ de 2003 , desde então a discussão em torno da implementação da Lei e suas Diretrizes é objeto de estudo de alguns pesquisadores. Segundo Almeida e Sanchez (2017), a Lei n ${ }^{\circ}$ 10.639/o3 é uma forma de reparar uma dívida social com a população negra, adquirida em função de um período escravista extenso, das políticas de embranquecimento, do mito da democracia racial e das práticas racistas. A implantação da Lei permitiria reconhecer e valorizar a história, a cultura e a identidade dos negros. Para isso, de acordo com os autores as instituições de ensino teriam que oferecer boas condições, materiais e professores com formação de qualidade.

Munanga (2005) afirma que a formação de professores, os quais não tiveram em sua base de formação a história da África, a cultura do negro no Brasil e a própria história do negro de um modo geral, se constitui no problema crucial das novas leis que 
implementaram o ensino desta disciplina nas escolas, pois a formação de qualidade dos alunos depende de uma formação de qualidade dos professores. Desse modo, o sucesso ou o fracasso das reformas dependerão do nível de convencimento e transformação dos docentes.

Pesquisas apontam que um problema para o processo de implementação da Lei ${ }^{\circ}$ 10.639/o3 é o despreparo e a ausência da temática étnico-racial nos cursos de formação inicial e continuada de professores, uma vez que as disciplinas nos cursos de licenciatura e os cursos de formação continuada, auxiliariam os professores a desenvolver projetos em conjunto com outros professores, a buscar materiais didáticos/pedagógicos e a alterar o currículo. Isto, porque a formação é capaz de sensibilizar, conscientizar e instrumentalizar os professores a exercerem práticas pedagógicas não discriminatórias e antirracistas (SILVÉRIO et al., 2016; PAULA; GUIMARÃES, 2014; GOMES, 2011; RIBEIRO, 2015).

Estudos destacam ser necessário que a universidade reconheça a diversidade étnico-racial brasileira e desenvolva uma ação efetiva na organização dos currículos. Estas instituições devem considerar os seus alunos enquanto futuros professores que necessitam dos conhecimentos e habilidades necessárias para lidar com a questão racial (OLIVEIRA, 2014; COELHO; COELHO, 2018).

Silva e Marques (2015), argumentam que a legislação em si não faz uma mudança. Mesmo que a legislação, as normativas governamentais, bem como os programas direcionados à questão da diversidade étnico-racial atuem de forma preponderante no cenário educacional, ainda assim, isso não se faz suficiente se não houver uma massificação de ações, principalmente no que se refere à formação continuada dos docentes. Neste sentido faz-se necessário um projeto de educação que rompa com o conhecimento eurocêntrico e reforce as políticas que assegurem a formação de professores (OLIVEIRA, 2018).

Neste mesmo sentido, Borges (2009); Santos (2010); Alves (2017); Dias; Cecatto (2015); Eugênio; Santana (2018) corroboram que a postura do professor tem raízes na sua formação acadêmica e refletirá na prática docente, isto porque os cursos de graduação 
ainda não possuem uma disciplina específica voltada para o estudo do continente africano e para o ensino de história da África. Sendo assim, existe uma necessidade de formação específica para os docentes, tanto na formação inicial quanto na formação continuada, para que a lei seja implementada.

A capacitação de professores, em todos os níveis de ensino, é de fundamental importância para a implementação da Lei Federal no 10.639/o3 e o enfrentamento das tensões em torno do racismo e preconceito no contexto escolar (CARDOSO et al., 2016), porém não é somente a formação inicial que resolveria o problema, pois como destaca Henriques; Cavalleiro (2005) a formação continuada é de fundamental importância, bem como o trato das questões raciais, e estas questões são definidas no planejamento da gestão escolar.

Acredita-se ser imprescindível a real discussão das relações étnico-raciais na formação inicial e continuada dos professores, pois estes profissionais precisam estar aptos e sensibilizados para o desenvolvimento da ERER. Enfim, de acordo com os autores supracitados, tanto a formação inicial ou continuada, falta de matérias didáticos, quanto o silenciamento em relação às questões étnico-raciais podem impedir a verdadeira implementação da legislação que contempla a ERER.

\section{Metodologia}

\subsection{Caracterização da pesquisa:}

Para alcançar os objetivos propostos optou-se pela realização de uma pesquisa aplicada descritiva e exploratória, pois tem como objetivo descrever, registrar e analisar as características com a intenção de aquisição de conhecimento com o propósito de proporcionar familiaridade com o problema (GIL, 2019; MARCONI; LAKATOS, 2018).

Quanto aos procedimentos trata-se de uma pesquisa de levantamento bibliográfico e documental, visto que analisa leis e documentos oficiais, bem como faz uma 
problematização fundamentada em bibliografias sobre a temática discutida (GIL, 2019; MARCONI; LAKATOS, 2009)

Quanto à abordagem trata-se de uma pesquisa quali-quantitativa, pois combina elementos quantitativos e qualitativos na análise dos dados tendo como propósito ampliar e aprofundar o entendimento dos resultados. A intenção é combinar elementos de análise a fim de se obter dados mais profundos (JOHNSON; ONWUEGBUZIE; TURNER, 2007; GERHARDT; SILVEIRA, 2009).

\subsection{Delineamento da pesquisa}

Foi feita uma análise documental de Leis, Pareceres, Resoluções e Portarias destinadas a Educação Básica e Superior com o objetivo de identificar na legislação educacional brasileira, pós os anos de 1990, referências sobre a formação de professores para trabalhar a ERER.

Foi feita a leitura e análise de documentos (leis, pareceres, resoluções e portarias) destinadas a Educação Infantil, Básica e Superior. Tomou-se como marco inicial a Lei de Diretrizes e Bases da Educação n ${ }^{\circ}$ 9.394/96 e a retrospectiva da legislação percorre 22

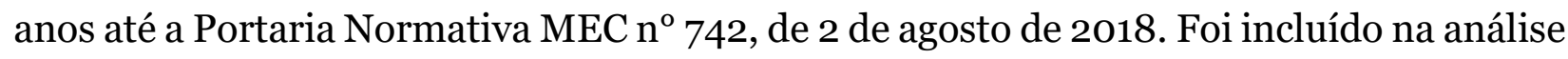
o documento Orientações e Ações para a Educação das Relações Étnico-Raciais de 2006 por ter significativa importância para a temática analisada.

Todos os documentos incluídos na análise (Leis, Pareceres, Resoluções, Portarias e Orientações) foram encontrados no http://portal.mec.gov.br/.

Incluiu-se na análise os documentos apresentados no quadro 1.

Quadro 1: Documentos incluídos na análise documental.

\begin{tabular}{|c|c|c|}
\hline 1 & Lei de Diretrizes e Bases da Educação nº 9.394/96; & 1996 \\
\hline 2 & Parecer CNE/CEB o5/97. Proposta de Regulamentação da Lei n ${ }^{\circ}$ 9.394/96; & 1997 \\
\hline 3 & Parecer CNE/CEB 12/97. Esclarece dúvidas sobre a Lei nº 9.394/96; & 1997 \\
\hline 4 & Lei $n^{\circ} 010172$, de 9 de janeiro de 2001 aprova o Plano Nacional de Educação-PNE; & 2001 \\
\hline 5 & Lei $n^{\circ}$ 10.639/o3, de o9 de janeiro de 2oo3; & 2003 \\
\hline 6 & $\begin{array}{l}\text { Parecer CNE/CP 3/2004. Diretrizes curriculares nacionais para a educação das } \\
\text { relações étnico-raciais e para o ensino de história e cultura afro-brasileira e africana; }\end{array}$ & 2004 \\
\hline
\end{tabular}




\begin{tabular}{|c|c|c|}
\hline 7 & $\begin{array}{l}\text { Resolução CNE/CEB no 1, de } 17 \text { de junho de 2004. Diretrizes Curriculares Nacionais } \\
\text { para a Educação das Relações Étnico-Raciais e para o Ensino de História e Cultura Afro- } \\
\text { Brasileira e Africana; }\end{array}$ & 2004 \\
\hline 8 & Orientações e Ações para a Educação das Relações Étnico-Raciais; & 2006 \\
\hline 9 & Lei n $^{\circ}$ 11.645/o8, de 10 março de 2008; & 2008 \\
\hline 10 & Lei no 12.014/o9, de 6 de agosto de 2009; & 2009 \\
\hline 11 & $\begin{array}{l}\text { Resolução CNE/CEB } \mathbf{n}^{\circ} \text { 5, de } 17 \text { de dezembro de 2009. Diretrizes Curriculares } \\
\text { Nacionais Para a Educação Infantil; }\end{array}$ & 2009 \\
\hline 12 & $\begin{array}{l}\text { Resolução CNE/CEB no } 7 \text {, de } 14 \text { de dezembro de 2010, as Diretrizes Curriculares } \\
\text { Nacionais para o Ensino Fundamental de nove anos; }\end{array}$ & 2010 \\
\hline 13 & 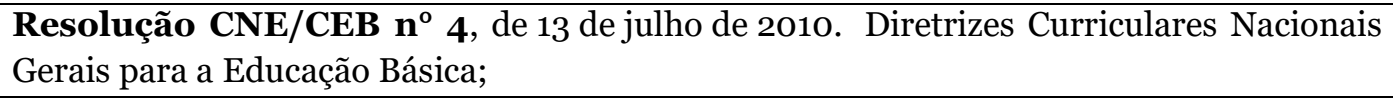 & 2010 \\
\hline 14 & $\begin{array}{l}\text { Resolução CNE/CEB no } 1 \text {, de } 30 \text { de maio de 2012. Diretrizes Nacionais para a Educação } \\
\text { em Direitos Humanos; }\end{array}$ & 2012 \\
\hline 15 & Lei no 13.005/14, de 25 de junho de 2014 aprova o Plano Nacional de Educação-PNE; & 2014 \\
\hline 16 & $\begin{array}{l}\text { Resolução CNE/CP no }{ }^{\circ} \text {, de } 1^{0} \text { de julho de 2015. Diretrizes Curriculares Nacionais para } \\
\text { a formação inicial em nível superior; }\end{array}$ & 2015 \\
\hline 17 & $\begin{array}{l}\text { Portaria Normativa MEC no } \mathbf{1 . 3 8 3} \text {, de } 31 \text { de outubro de 2017. Aprova, em extrato, os } \\
\text { indicadores do Instrumento de Avaliação de Cursos de Graduação; }\end{array}$ & 2017 \\
\hline 18 & $\begin{array}{l}\text { Portaria Normativa MEC n }{ }^{\circ} \mathbf{2 3} \text {, de } 21 \text { de dezembro de 2017. Dispõe sobre o fluxo dos } \\
\text { processos de credenciamento e recredenciamento de instituições de educação superior e } \\
\text { de autorização, reconhecimento e renovação de reconhecimento de cursos superiores; }\end{array}$ & 2017 \\
\hline 19 & $\begin{array}{l}\text { Portaria Normativa MEC } \mathbf{n}^{\circ} \mathbf{7 4 2} \text {, de } 2 \text { de agosto de } 2018 \text {. Altera a Portaria Normativa } \\
\mathrm{n}^{0} 23 \text {, de } 21 \text { de dezembro de } 2017 \text {, que dispõe sobre os fluxos dos processos de } \\
\text { credenciamento e recredenciamento de instituições de educação superior e de autorização, } \\
\text { reconhecimento e renovação de reconhecimento de cursos superiores. }\end{array}$ & 2018 \\
\hline
\end{tabular}

Fonte: Elaborado pelas autoras (2020).

\section{Resultados e Discussão}

$\mathrm{Na}$ análise dos 19 documentos destacamos, em ordem cronológica, as referências sobre a formação de professores para trabalhar a ERER.

A Lei de Diretrizes e Bases da Educação nº 9.394/96, que estabelece as diretrizes e bases da educação nacional e regulamenta a educação infantil, ensino fundamental e educação superior, em seu interior no que diz respeito as relações étnico-raciais, traz no Art. 26 " $\$ 4^{\circ} \mathrm{O}$ ensino da História do Brasil levará em conta as contribuições das diferentes 
culturas e etnias para a formação do povo brasileiro, especialmente das matrizes indígena, africana e europeia" (BRASIL, 1996a, p. 20).

No artigo Art. 26-A e Art. 79-B estabelece a obrigatoriedade do ensino da história e cultura afro-brasileira e indígena, no âmbito de todo o currículo escolar, especialmente nas áreas de educação artística, literatura e história brasileira (BRASIL,1996a).

No tocante à formação inicial podemos perceber que no Art. 62 determina que "§ $1^{\circ}$ A União, o Distrito Federal, os Estados e os Municípios, em regime de colaboração, deverão promover a formação inicial, a continuada e a capacitação dos profissionais de magistério" (BRASIL, 1996a, p. 42), temos ainda em seu Título VI - Dos Profissionais da Educação, especificações e determinações sobre a formação inicial e continuada dos profissionais da educação, mas não apresenta nada específico em relação a formação destes profissionais para trabalharem com as relações étnico-raciais no contexto escolar.

O Parecer CNE/CEB 05/97 aprovado em 7 de maio de 1997 consiste em uma orientação mais ampla para os sistemas e instituições de ensino a respeito de dispositivos sobre os quais ainda pudesse estar pairando alguma dúvida sobre a Lei nº 9.394/96.

Os esclarecimentos relativos aos profissionais da educação sobre a formação de professores do ensino básico, destaca que a LDB determina a obrigatoriedade de formação em nível superior e na licenciatura plena. Quanto à formação de professores para a educação infantil e as quatro primeiras séries do ensino fundamental, admite-se a formação em nível médio, na modalidade Normal, porém determina que ao final da Década da Educação, todos os docentes deverão ter curso superior (BRASIL, 1997). Nenhum dos esclarecimentos trazidos neste parecer se direcionam para a formação específica dos professores para a implementação do artigo Art. 26-A e Art. 79-B da Lei no 9.394/96.

O Parecer CNE/CEB 12/97 vem complementar o Parecer CNE/CEB 05/97 para esclarecer dúvidas sobre a Lei ${ }^{\circ}$ 9.394/96. Este parecer não traz nada relacionado a formação de professores e não menciona nada em relação a Educação das Relações Étnico-Raciais. 
A lei $\mathrm{n}^{\circ}$ 010172, de 9 de janeiro de 2001 aprova o Plano Nacional de Educação e dá outras providências, com duração de dez anos. Uma das prioridades do PNE 2001 é a valorização dos profissionais da educação, destacando que deve ser dada particular atenção à formação inicial e continuada dos professores.

Especificamente sobre a educação para as relações étnico-raciais, no item Educação Indígena, a formação objetiva a capacitação dos professores para a elaboração de currículos e programas específicos para as escolas indígenas. Na meta 16, estabelece e assegura a qualidade de programas contínuos de formação sistemática do professorado indígena (BRASIL, 2001).

A qualificação dos professores é apontada como um dos maiores desafios para o Plano Nacional de Educação, destacando que o Poder Público precisa se dedicar à solução deste problema. Na formação, determina-se a inclusão das questões relativas à educação dos alunos com necessidades especiais, das questões de gênero e de etnia (BRASIL, 2001). Também na meta 21 do item destinado a formação de professores, menciona a inclusão, nos currículos e programas dos cursos de formação de profissionais da educação, temas relativos a história, a cultura, os conhecimentos, as manifestações artísticas e religiosas afro-brasileiras e das sociedades indígenas.

A Lei $\mathrm{n}^{\circ} 10.639$ foi promulgada no dia 9 de janeiro de 2003. Esta Lei altera a Lei $\mathrm{n}^{\circ}$ 9.394, de 20 de dezembro de 1996, para incluir no currículo oficial da Rede de Ensino a obrigatoriedade da temática "História e Cultura Afro-Brasileira" e também incluir no calendário escolar o dia 20 de novembro como 'Dia Nacional da Consciência Negra'. No interior da Lei não se aplica nada relacionado a formação de professores para implementar o que determina a referida Lei (BRASIL, 2003).

O parecer $\mathrm{CNE} / \mathrm{CP} 3 / 2004$, aprovado em 10 de março de 2004 tem como objetivo atender os propósitos expressos na Indicação CNE/CP 6/2002, e regulamentar a alteração feita à Lei de Diretrizes e Bases da Educação Nacional pela Lei n ${ }^{\circ}$ 10.639/2003.

O Parecer destaca a necessidade de professores qualificados para o ensino das diferentes áreas de conhecimentos e que sejam capazes de direcionar positivamente as 
relações entre pessoas de diferentes pertencimentos étnico-raciais, incentivando o respeito e corrigindo posturas, atitudes e palavras preconceituosas.

Neste sentido, aponta ser necessário investimento para que os professores além de sua formação inicial também recebam formação para perceberem a importância das questões étnico-raciais e poderem construir estratégias pedagógicas que possam auxiliar positivamente as relações étnico-raciais. (BRASIL, 2004).

Aponta que os sistemas de ensino e os estabelecimentos de Educação Básica precisarão providenciar instalação de grupos de trabalho com o intuito de discutir, coordenar e planejar a formação de professores para atenderem a implementação da Educação das Relações Étnico-Raciais (BRASIL, 2004).

Destaca a necessidade de se introduzir nos cursos de formação de professores e de outros profissionais da educação conceitos e bases teóricas sobre o racismo, discriminações, intolerância, preconceito, estereótipo, raça, etnia, cultura, classe social, diversidade, diferença, multiculturalismo, também de práticas pedagógicas, de materiais e de textos didáticos, com o objetivo de promover uma reeducação das relações étnicoraciais e do ensino e aprendizagem da História e cultura dos Afro-brasileiros e dos Africanos (BRASIL, 2004).

O documento apresenta especificações relacionadas as questões étnico-raciais e valorização da diversidade, bem como o conhecimento e formação dos professores em relação a estes direcionamentos. Atenta-se para os processos de formação continuada de professores, inclusive de docentes no Ensino Superior, o que favorece para o processo de aplicação da Educação das Relações Étnico-Raciais.

A Resolução $\mathrm{n}^{0}$ 1, de 17 de junho de 2004 institui Diretrizes Curriculares Nacionais para a Educação das Relações Étnico-Raciais e para o Ensino de História e Cultura AfroBrasileira e Africana, as quais devem ser observadas pelas Instituições de ensino e de modo especial, por Instituições que desenvolvem programas de formação inicial e continuada de professores. O documento constitui-se em orientações, princípios e fundamentos para o planejamento, execução e avaliação da educação, apresenta como 
meta, a promoção de uma educação que busca desenvolver cidadãos atuantes e conscientes de uma sociedade multicultural e pluriétnica em que vivem, objetivando promover relações étnico-sociais positivas (BRASIL, 2004).

Esta Resolução no Art. $4^{\circ}$ destaca a importância da integração entre diferentes instituições, inclusive as de formação de professores, para a concretização das Diretrizes Curriculares Nacionais para a Educação das Relações Étnico-Raciais e para o Ensino de História e Cultura Afro-Brasileira e Africana.

As Orientações e Ações para a Educação das Relações Étnico-Raciais é um documento publicado em 2006 que objetiva orientar o processo de implementação da Lei $\mathrm{n}^{\mathrm{o}}$ 10.639/03 e direcionar a aplicação das Diretrizes Curriculares Nacionais para a Educação das Relações Étnico-Raciais e para o Ensino de História e Cultura AfroBrasileira e Africana, com correlação a faixa etária e cada nível de ensino.

Este documento entra em análise por ter fundamental importância no processo de implementação de uma educação que reconheça a diversidade étnico-racial, portanto ressalta-se o que este apresenta em relação à formação dos professores.

O documento menciona que a educação sugere preocupações relacionadas ao material didático-pedagógico e à formação de professores, pois as escolas precisam estar atentas às atitudes racistas, uma vez que muitas situações de preconceito e racismo são ignoradas pelos profissionais da educação, o que prejudica os alunos negros. Para que aconteça a implementação das DCN's para a ERER os sistemas de ensino devem supervisionar, orientar e promover a formação de professores e professoras, para que estejam capacitados a desenvolver uma educação que respeite a diversidade (BRASIL, 2006).

O documento destaca que os esforços para inserção das DCN's para a ERER devem estar articulados as políticas educacionais da educação superior, principalmente as Diretrizes Curriculares Nacionais para Formação de Professores para Educação Básica e Diretrizes Específicas dos Cursos de Licenciaturas (BRASIL, 2006). 
A Lei 11.645 de 10 de março de 2008 altera a Lei ${ }^{\circ}$ 10.639/o3 e inclui a valorização e a inclusão da cultura indígena no currículo escolar. A Lei 11.645 estabelece em seu "Art. 26-A. Nos estabelecimentos de ensino fundamental e de ensino médio, públicos e privados, torna-se obrigatório o estudo da história e cultura afro-brasileira e indígena" (BRASIL, 2008, p. 1). Porém a Lei $\mathrm{n}^{\circ} 10.639$ e a Lei $\mathrm{n}^{\circ}$ 11.645, em seu interior, não fazem referência à formação de professores para conduzir esse processo de inclusão da história e cultura afro-brasileira e indígena no currículo escolar.

A Lei $n^{\circ}$ 12.014 altera o Art. 61 da Lei nº 9.394, de 20 de dezembro de 1996 e tem como objetivo discriminar as categorias de trabalhadores que são considerados profissionais da educação escolar básica.

Quanto a formação de professores a Lei traz em seu parágrafo único que a formação dos profissionais da educação baseia-se em três fundamentos de modo a atender às especificidades do exercício de suas atividades, e aos objetivos das diferentes etapas e modalidades da educação básica:

I - a presença de sólida formação básica, que propicie o conhecimento dos fundamentos científicos e sociais de suas competências de trabalho; II - a associação entre teorias e práticas, mediante estágios supervisionados e capacitação em serviço; III - o aproveitamento da formação e experiências anteriores, em instituições de ensino e em outras atividades (BRASIL, 2009, p. 1).

Contudo esta Lei não especifica nada em relação a formação dos professores para a Educação das Relações Étnico-Raciais.

A Resolução $\mathrm{n}^{0}$ 5, de 17 de dezembro de 2009 institui as Diretrizes Curriculares Nacionais para a Educação Infantil, as quais objetivam orientar as políticas públicas na área e também na elaboração, planejamento, execução e na avaliação das propostas pedagógicas e curriculares para esta etapa. No Art. $6^{\circ}$ que diz respeito as propostas pedagógicas, aponta princípios a serem seguidos, dentre eles: "I - Éticos: da autonomia, da responsabilidade, da solidariedade e do respeito ao bem comum, ao meio ambiente e às diferentes culturas, identidades e singularidades” (BRASIL, 2009, p. 2). 
No Art. $7^{\circ}$ enfatiza que a proposta pedagógica das instituições de Educação Infantil deve cumprir sua função sociopolítica e pedagógica buscando romper com relações de dominação etária, socioeconômica, étnico-racial, de gênero, regional, linguística e religiosa. No Art. $8^{\circ}$ aponta que as crianças precisam conhecer as contribuições históricoculturais dos povos indígenas, afrodescendentes, asiáticos, europeus e de outros países da América, bem como reconhecer, valorizar, respeitar e interagir com crianças e com as histórias e as culturas africanas, afro-brasileiras, a fim de se combater ao racismo e à discriminação (BRASIL, 2009).

Esta Resolução traz apontamentos para o reconhecimento e valorização da diversidade étnico-racial, todavia não especifica como os profissionais da educação devem ser preparados para a função de mediadores desse processo na Educação Infantil.

A Resolução $\mathrm{n}^{\mathrm{O}}$ 7, de 14 de dezembro de 2010 fixa as Diretrizes Curriculares Nacionais para o Ensino Fundamental de nove anos a serem observadas na organização curricular dos sistemas e instituições de ensino. A resolução apresenta no Art. $5^{\circ}$ que um dos fundamentos a serem seguidos ao lado das políticas universais são as políticas reparadoras que assegurem apoio aos grupos sociais em desvantagem (BRASIL, 2010).

Em relação aos princípios a serem seguidos no Art. $6^{\circ}$ aponta princípios éticos de justiça, solidariedade, liberdade, autonomia, respeito buscando combater preconceitos de origem, raça, sexo, cor, idade e outras formas de discriminação (BRASIL, 2010). No Art. 15 especifica que " $\$ 2^{\circ} \mathrm{O}$ ensino de História do Brasil levará em conta as contribuições das diferentes culturas e etnias para a formação do povo brasileiro, especialmente das matrizes indígena, africana e europeia (art. 26, $\S 4^{\circ}$, da Lei nº 9.394/96) “(BRASIL, 2010, p. 4).

Também determina no Art. 15 que o ensino de história e das culturas indígena e afro-brasileira deverão assegurar conhecimento e o reconhecimento desses povos na constituição da nação brasileira (BRASIL, 2010). No Art. 16 aponta a responsabilidade do sistema de ensino em oferecer a produção e a disseminação de materiais subsidiários para 
o trabalho dos professores, os quais possam contribuir para a eliminação de discriminações, racismo, sexismo, homofobia e outros preconceitos (BRASIL, 2010).

Quanto a implementação destas Diretrizes, o documento reforça ser um compromisso solidário dos sistemas e redes de ensino. No Art. 48, o documento ressalta que são necessários especiais esforços quanto à formação dos professores das modalidades específicas do Ensino Fundamental e para os que trabalham nas escolas do campo, indígenas e quilombolas (BRASIL, 2010).

A Resolução CNE/CEB no 4, de 13 de julho de 2010 define Diretrizes Curriculares Nacionais Gerais para as etapas e modalidades da Educação Básica. No Art. 9 determina dentre os seus requisitos a importância da valorização dos profissionais da educação, apontando ser necessário oferecer-lhes um programa de formação continuada. (BRASIL, 2010). Apresenta no Art. 41 que as unidades educacionais precisam desenvolver uma pedagogia que respeite as especificidades étnico-culturais dos alunos, bem como oferecer formação específica aos docentes para desenvolver o processo educacional com qualidade (BRASIL, 2010).

A Resolução faz apontamentos referentes a formação inicial e continuada dos professores. Trazendo no Art. 44 que o projeto político-pedagógico precisa contemplar a formação inicial e continuada dos profissionais da educação, regentes e não regentes. No Art. 57 traz a exigência de programas de formação inicial e continuada de docentes e não docentes e no Art. 58 destaca que a formação inicial não é suficiente para o desenvolvimento dos conhecimentos, saberes e habilidades, por isso um programa de formação continuada dos profissionais da educação precisa ser contemplado no projeto político-pedagógico (BRASIL, 2010). Porém o documento não trata explicitamente da formação de professores para desenvolver um trabalho que respeite as diferenças étnicoraciais.

A Resolução $\mathrm{n}^{0}$ 1, de 30 de maio de 2012 estabelece as Diretrizes Nacionais para a Educação em Direitos Humanos (EDH), as quais devem ser observadas pelos sistemas de ensino e suas instituições. Em seu Art. $3^{\circ}$ menciona a importância do "III - 
reconhecimento e valorização das diferenças e das diversidades” (BRASIL, 2012, p. 1), porém não menciona nada relativo a formação de professores.

A Lei no 13.005, de 25 de junho de 2014 aprova o Plano Nacional de Educação PNE, com vigência para 10 anos. O PNE em seu Art. $2^{\circ}$ traz como uma de suas diretrizes a "III - superação das desigualdades educacionais, com ênfase na promoção da cidadania e na erradicação de todas as formas de discriminação (BRASIL, 2014, p.1).

Estabelece em sua meta 8 igualar a escolaridade entre negros e não negros declarados ao IBGE até 2024 (BRASIL, 2014). Na meta 12 traz como estratégia aumentar o atendimento às populações do campo, comunidades indígenas e quilombolas, objetivando aumentar o acesso, permanência e conclusão, também promover a formação de profissionais para atuação nessas populações (BRASIL, 2014).

Na meta 13 apresenta como estratégia buscar a melhoria da qualidade dos cursos de pedagogia e licenciaturas, aplicando avaliações aprovadas pela Comissão Nacional de Avaliação da Educação Superior - CONAES, com o objetivo de promover aos graduandos a aquisição das qualificações necessárias para conduzir o processo pedagógico de seus futuros discentes, proporcionando formação geral e específica com a prática didática, bem como a educação das relações étnico-raciais, a diversidade e as necessidades das pessoas com deficiência (BRASIL, 2014).

A Lei expõe em anexo metas e estratégias a serem alcançadas para a melhoria da qualidade da educação. Dentre elas, uma específica, para a formação de professores, mas nada direcionado para as relações étnico-raciais. Na Meta 16 apresenta a necessidade de oferecer até 2024 pós-graduação a 50\% dos professores da educação básica e proporcionar a todos estes profissionais formação continuada em sua área de atuação, atendendo as necessidades e contextualizações dos sistemas de ensino (BRASIL, 2014).

Percebe-se o destaque da importância da formação inicial e continuada dos professores para que se possa atingir as metas estabelecidas e obter-se melhoria na qualidade educacional, porém nenhuma menção direta a formação para as relações étnico-raciais. 
A Resolução $\mathrm{CNE} / \mathrm{CP} \mathrm{n}^{0}$ 2, de $1^{\circ}$ de julho de 2015 institui as Diretrizes Curriculares Nacionais para a Formação Inicial e Continuada em Nível Superior de Profissionais do Magistério para a Educação Básica. A Resolução considera que a valorização da diversidade étnico-racial constitui um dos princípios vitais para a melhoria e democratização da gestão e do ensino. Apresenta no Art. $3^{\text {o }}$ que a formação dos profissionais do magistério, tendo compromisso com os aspectos sociais, políticos e éticos contribui para a formação de uma nação soberana, democrática, justa, inclusiva a qual pode promover a emancipação dos indivíduos e grupos sociais, atendendo ao reconhecimento e à valorização da diversidade e combatendo toda forma de discriminação (BRASIL, 2015).

Ainda no Art. $3^{\circ}$ aponta a importância da formação docente para atender as questões socioambientais, éticas, estéticas e relativas à diversidade étnico-racial, de gênero, sexual, religiosa, de faixa geracional e sociocultural para promover os princípios de igualdade no contexto educacional (BRASIL, 2015). Destaca no Art. $5^{\circ}$ que o processo de formação dos docentes necessita estar atento para à concretização da educação inclusiva por meio do respeito as diferenças, buscando o reconhecimento e valorização da diversidade étnico-racial, de gênero, sexual, religiosa, de faixa geracional (BRASIL, 2015).

No Art. $8^{\circ}$ é apresentado que os cursos de formação inicial em nível superior deverão estar hábeis a identificar aspectos e problemas socioculturais e educacionais, para que possa proporcionar a superação de exclusões sociais, étnico-raciais, econômicas, culturais, religiosas, políticas, de gênero e sexuais (BRASIL, 2015, p. 8).

Nas especificações para os cursos de formação pedagógica para graduados não licenciados, cursos de segunda Licenciatura e cursos de formação inicial de professores para a educação básica em nível superior apresentam nos Art. 13, 14 e 15

a necessidade de cursos de formação que garantam em seus currículos e ofereçam aos graduandos conteúdos relacionados ao reconhecimento da diversidade étnico-racial.

A Portaria MEC n ${ }^{0}$ 1.383, de 31 de outubro de 2017 aprova os indicadores dos Instrumentos de Avaliação de Cursos de Graduação para os atos de autorização, 
reconhecimento e renovação de reconhecimento nas modalidades presencial e a distância. Dentre os pesos dos eixos para os atos de autorização nas modalidades presencial e a distância está a titulação e formação do corpo de tutores do curso, mas no documento não consta nada sobre as relações étnico-raciais.

Dispõe sobre o fluxo dos processos de credenciamento e recredenciamento de instituições de educação superior e de autorização, reconhecimento e renovação de reconhecimento de cursos superiores. Esta Portaria não traz nenhuma especificação referente a formação de professores, e nem formação de professores para ERER.

A Portaria Normativa MEC $\mathrm{n}^{0}$ 742, de 2 de agosto de 2018 dispõe sobre os fluxos dos processos de credenciamento e recredenciamento de instituições de educação superior e de autorização, reconhecimento e renovação de reconhecimento de cursos superiores, esta que altera a Portaria Normativa $n^{0} 23$, de 21 de dezembro de 2017, não apresenta nenhuma referência à formação de professores e formação para ERER.

Dos 19 documentos incluídos na análise, dentre Leis, Pareceres, Resoluções, Portarias e Orientações, 6 destes documentos apresentam referências específicas para a formação de professores para a ERER; 4 apresentam referências para as questões étnicoraciais; 5 trazem referências para a formação inicial e continuada de professores e 4 não trazem referências sobre a formação de professores para a implementação da ERER e nem sobre as relações étnico-raciais.

Destaca-se no quadro 2 os documentos que apresentam ou não referências sobre a formação de professores, formação de professores para a ERER e questões relativas as relações étnico-raciais. 
Quadro 2: Documentos e as referências encontradas na análise.

\begin{tabular}{|c|c|c|}
\hline Referências nos documentos & Legislação Educacional & \\
\hline \multirow{6}{*}{$\begin{array}{l}\text { Apresentam referências } \\
\text { específicas para a formação } \\
\text { de professores para a ERER. }\end{array}$} & Lei $\mathrm{n}^{\circ}$ 010172, de 9 de janeiro de 2001 & 2001 \\
\hline & Parecer CNE/CP 3/2004; & 2004 \\
\hline & Resolução $n^{0} 1 / 2004$ & 2004 \\
\hline & $\begin{array}{l}\text { Orientações e Ações para a Educação das Relações } \\
\text { Étnico-Raciais/2006; }\end{array}$ & 2006 \\
\hline & Resolução n ${ }^{0}$ 7/2010; & 2010 \\
\hline & Resolução CNE/CP nº 2/2015. & 2015 \\
\hline \multirow{4}{*}{$\begin{array}{l}\text { Apresentam referências para } \\
\text { as questões étnico-raciais. }\end{array}$} & Lei $\mathrm{n}^{\circ}$ 10.639/2003; & 2003 \\
\hline & Lei $\mathrm{n}^{\circ}$ 11.645/2008; & 2008 \\
\hline & Resolução $n^{0}$ 5/2009; & 2009 \\
\hline & Resolução $\mathrm{n}^{0} \mathrm{1} / 2012$. & 2012 \\
\hline \multirow{5}{*}{$\begin{array}{l}\text { Apresentam referências para } \\
\text { a formação inicial e } \\
\text { continuada de professores. }\end{array}$} & A Lei de Diretrizes e Bases da Educação n ${ }^{\circ}$ 9.394/96; & 1996 \\
\hline & Parecer CNE/CEB 05/97; & 1997 \\
\hline & Lei no 12.014/2009; & 2009 \\
\hline & Resolução CNE/CEB no 4/2010; & 2010 \\
\hline & Lei $\mathrm{n}^{0} 13.005 / 2014$ & 2014 \\
\hline \multirow{4}{*}{$\begin{array}{l}\text { Não apresentam referências } \\
\text { sobre a formação de } \\
\text { professores d para } \\
\text { implementação da ERER e } \\
\text { nem sobre as relações étnico- } \\
\text { raciais. }\end{array}$} & O Parecer CNE/CEB 12/97; & 1997 \\
\hline & Portaria MEC n⿳0 1.383/2017; & 2017 \\
\hline & Portaria Normativa $\mathrm{n}^{0} 23 / 2017$ & 2017 \\
\hline & Portaria Normativa MEC n ${ }^{0} 742 / 2018$. & 2018 \\
\hline
\end{tabular}

Fonte: Elaborado pelas autoras (2020).

Observa-se que a maioria dos documentos analisados estão atentos à formação de professores para a ERER, a formação inicial e continuada de professores e as questões étnico-raciais.

Um dado a ser mencionado é que documentos tão importantes para a educação Superior como a Portaria MEC $n^{0} 1.383$, de 31 de outubro de 2017 que aprova os indicadores dos Instrumentos de Avaliação de Cursos de Graduação para os atos de autorização; A Portaria Normativa $\mathrm{MEC}^{0}{ }^{742}$, de 2 de agosto de 2018 que dispõe sobre os fluxos dos processos de credenciamento e recredenciamento de instituições de educação superior e de autorização, reconhecimento e renovação de reconhecimento de cursos superiores sequer mencionam algo sobre as relações étnico-raciais. 
A discussão sobre a formação de professores pautada na literatura aponta que um problema para a implementação da ERER encontra-se na formação inicial e continuada para os professores. Desse modo, nota-se que a legislação educacional traz suporte para a implementação da ERER, porém esta legislação não se impõe por si própria, estando sujeita, em sua aplicação, à formação e capacitação dos professores.

\section{CONSIDERAÇÕES FINAIS}

As políticas educacionais ou políticas de ações afirmativas que garantem a ERER são de fundamental importância para o processo de valorização da diversidade no contexto escolar. Estas políticas são fundamentais para se garantir a população negra o acesso e a permanência na escola, usufruindo de uma educação de qualidade.

Sabe-se que muito se avançou na legislação brasileira no sentido de reconhecer importantes segmentos como portadores de direitos, mas o que está prescrito na lei nem sempre corresponde à realidade (OLIVEIRA, 2014). Isto foi evidenciado pela literatura, quando esta aponta embates como a formação inicial e continuada de professores e a falta de materiais didáticos para a implementação da ERER.

Com as leituras das Leis, Pareceres, Resoluções, Portarias e Orientações destinadas a Educação Infantil, Básica e Superior, percebeu-se que a Lei n ${ }^{\circ}$ 010172, de 9 de janeiro de 2001; o Parecer CNE/CP 3/2004; Resolução no 1/2004; Orientações e Ações para a Educação das Relações Étnico-Raciais/2006; Resolução no 7/2010; Resolução CNE/CP $\mathrm{n}^{\mathrm{O}}$ 2/2015 apresentam determinações para a formação dos professores para a ERER, ressaltando que eles precisam estar preparados e qualificados para cumprirem o seu papel de educadores, proporcionando uma melhoria nas relações étnico-raciais no contexto escolar.

A Lei n ${ }^{\circ}$ 10.639/2003; a Lei no 11.645/2008; a Resolução no 5/200; a Resolução $\mathrm{n}^{\mathrm{o}}$ 1/2012 trazem aspectos e determinações relacionados as questões étnico-raciais e 
valorização da diversidade, mas não apresentam direcionamentos quanto a formação de professores para desenvolver a ERER.

A Lei de Diretrizes e Bases da Educação n ${ }^{\circ}$ 9.394/96; Parecer CNE/CEB 05/97; a Lei $n^{0}$ 12.014/2009; a Resolução CNE/CEB no 4/2010 e Lei no 13.005/2014 ressaltam a importância da formação inicial e continuada de professores, porém não trazem especificamente direcionamentos para a formação relacionada às relações étnico-raciais.

O Parecer CNE/CEB 12/97; a Portaria MEC no 1.383/2017; a Portaria Normativa $n^{0}$ 23/2017 e a Portaria Normativa MEC n ${ }^{0} 742 / 2018$ não mencionam sobre a formação de professores e nem relações étnico-raciais.

Nota-se que a partir da promulgação da Lei $\mathrm{n}^{\circ}$ 10.639/o3, a temática das relações étnico-raciais se intensifica e amplia-se a discussão para a formação de professores para a implementação da ERER. Portanto considera-se que a referida lei representa um marco legal de fundamental importância para a garantia de discussões sobre a temática das relações raciais, bem como a garantia da valorização da cultura afro-brasileira e africana no contexto escolar.

Vale ressaltar que o FUNDEF (Fundo de Manutenção e Desenvolvimento do Ensino Fundamental e da Valorização do Magistério) traz em suas prescrições que a atualização e o aprofundamento dos conhecimentos profissionais dos professores deverão ser promovidos com programas de aperfeiçoamento profissional continuado. Uma parcela desse recurso poderia ser destinada à formação específica à ERER, uma vez que esta formação é tão necessária para a concretização de uma educação antirracista.

Com base na literatura observou-se que um problema para a implementação da ERER encontra-se na formação inicial e continuada para os professores, uma vez que na análise documental percebeu-se que a legislação educacional traz referências e suporte para a sua implementação, porém esta legislação não se impõe por si própria, estando sujeita, em sua aplicação, à formação e capacitação dos professores. Espera-se que o estudo instigue a reflexão sobre a importância da formação de professores para a implementação das políticas educacionais no âmbito escolar. 


\section{Referências}

ALMEIDA, M. A.B.; SANCHEZ, L. P. Implementação da Lei 10.639/03 - competências, habilidades e pesquisas para a transformação social. Pró-posições, v. 28, n.1 p.55-80, jan./abr. 2017.

ALVES, M. M. Lei 10.639/o3, formação docente e NEABs: a democratização do currículo como um desafio para a educação brasileira. Cadernos do Aplicação, Porto Alegre, v. 30, p. 33-47, jan./dez. 2017.

AZEVEDO, G. F. A. M.; AZEVEDO, A. N. M. Políticas educacionais dos anos 90 e os impactos na gestão da educação Brasileira. Braz. Ap. Sci. Rev., Curitiba, v. 3, n. 3, p. 1469-1483 mai./jun. 2019.

BORGES, J. A. Ambígua África, memórias e representações da África Antiga no livro didático: Egito, reinos e impérios africanos. 2009. Dissertação (Mestrado em Memória: Linguagem e Sociedade) - Programa de Pós-Graduação em Memória: Linguagem e Sociedade, Universidade Estadual do Sudoeste da Bahia, Vitória da Conquista, 2009.

BRASIL. Orientações e Ações para a Educação das Relações Étnico-Raciais. Brasília: SECAD, 2006.

BRASIL. Conselho Nacional de Educação. Parecer CNE/CP 3/2004. Diretrizes curriculares nacionais para a educação das relações étnico-raciais e para o ensino de história e cultura afro-brasileira e africana. Brasília, 2004a.

BRASIL. Conselho Nacional de Educação. Parecer CNE/CEB 05/97. Proposta de Regulamentação da Lei 9.394/96. Brasília, MEC, 1997.

BRASIL. Conselho Nacional de Educação. Parecer CNE/CEB 12/97. Esclarece dúvidas sobre a Lei $n^{\circ}$ 9.394/96 (Em complemento ao Parecer CEB no 5/97). Brasília, MEC, 1997.

BRASIL. Lei no 10.639/o3, de og de janeiro de 2003. Brasília: MEC, 2003.

BRASIL. Lei no 9.394/96, de 20 de dezembro de 1996. Brasília: MEC, 1996a.

BRASIL. Lei no . 9.424, de 24 de dezembro de 1996. Regulamenta o FUNDEF. Diário Oficial da União, Brasília, 1996b. 
BRASIL. Lei no 11.645, de 10 março de 2oo8. Brasília: MEC, 2008.

BRASIL. Lei no 13.005, de 25 de junho de 2014. Aprova o Plano Nacional de Educação - PNE - e dá outras providências. Brasília, 2014.

BRASIL. Lei no o10172, de 9 de janeiro de 2001. Aprova o Plano Nacional de Educação - PNE - e dá outras providências. Brasília, 2001.

BRASIL. Lei no 12.014 de 6 de agosto de 2oo9. Altera o art. 61 da Lei no 9.394, de 20 de dezembro de 1996, com a finalidade de discriminar as categorias de trabalhadores que se devem considerar profissionais da educação. Brasília, MEC, 2009.

BRASIL. CNE/CEB - Resolução, no 5 , de 17 de dezembro de 2009. Diretrizes Curriculares Nacionais Para a Educação Infantil. Brasília: MEC, 2009.

BRASIL. CNE/CEB - Resolução $n^{0}$ 1, de 17 de junho de 2004. Diretrizes Curriculares Nacionais para a Educação das Relações Étnico-Raciais e para o Ensino de História e Cultura Afro-Brasileira e Africana. Brasília: MEC, 2004.

BRASIL. CNE/CEB - Resolução n ${ }^{0}$ 7, de 14 de dezembro de 2010, as Diretrizes Curriculares Nacionais para o Ensino Fundamental de nove anos. Brasília: MEC, 2010.

BRASIL. CNE/CEB - Resolução no 4, de 13 de julho de 2010. Diretrizes Curriculares Nacionais Gerais para a Educação Básica. Brasília: MEC, 2010.

BRASIL. CNE/CEB - Resolução no 1 , de 30 de maio de 2012. Diretrizes Nacionais para a Educação em Direitos Humanos. Brasília: MEC, 2012.

BRASIL. CNE/CP- Resolução $n^{0}$ 2, de $1^{0}$ de julho de 2015. Diretrizes Curriculares Nacionais para a formação inicial em nível superior. Brasília: MEC, 2015.

BRASIL. Ministério da Educação. Portaria MEC n⿳ $\mathbf{n}^{\mathbf{1}} \mathbf{3 8 3}$, de 31 de outubro de 2017. Aprova, em extrato, os indicadores do Instrumento de Avaliação de Cursos de Graduação. Brasília, 2017b.

BRASIL. Ministério da Educação. Portaria Normativa MEC no 23, de 21 de dezembro de 2017. Dispõe sobre o fluxo dos processos de credenciamento e recredenciamento de instituições de educação superior e de autorização, reconhecimento e renovação de reconhecimento de cursos superiores. Brasília. 2017. 
BRASIL. Ministério da Educação. Portaria Normativa MEC no 742 , de 2 de agosto de 2018. Altera a Portaria Normativa $n^{0} 23$, de 21 de dezembro de 2017, que dispõe sobre os fluxos dos processos de credenciamento e recredenciamento de instituições de educação superior e de autorização, reconhecimento e renovação de reconhecimento de cursos superiores. Brasília, 2017.

BRASIL. Ministério da Educação. Secretaria Executiva. Documento Referência da Conferência Nacional de Educação (CONAE 2014). Brasília: MEC, 2012. v. 1.

CARDOSO, P. J. F.; CARVALHO, S. B.; RASCKE, K. L.; SANTOS, C. S.; SILVA, C. M. Formação continuada em Educação das Relações Étnico-Raciais: o(a) professor(a) tutor(a) na construção do conhecimento. Revista Ibero-Americana de Estudos em Educação, v. 11, n. 3, p.1389-1409, 2016.

CAVALLEIRO, E. Educação anti-racista: compromisso indispensável para um mundo melhor. In: Racismo e anti-racismo na educação: Repensando nossa escola. CAVALLEIRO, Eliane (Org.) São Paulo: Selo Negro Edições, 2001, 213 p.

COELHO, M. C.; COELHO, W. N. B. As Licenciaturas em História e a Lei 10.639/o3 percursos de formação para o trato com a diferença? Educação em Revista, Belo Horizonte, v. 34, p. 1-39, 2018.

DANTAS, O. M. A. N.; FREITAS, E. R. A escola de Kafka: a legislação educacional do Brasil e seu reflexo na sociedade. Revista eletrônica Pesquiseduca, Santos, v. 11, n. 25, p. 325-343, 2020.

DEMO, P. Política social do conhecimento e educação. Revista de Política e Administração da Educação. Associação Nacional de Política e Administração da Educação. v. 14, n. 2, p. 175-193, jul./dez., 1998.

DIAS, E. C.; CECATTO, A. Entre teoria e prática: a formação docente e a apropriação da Lei 10.639/2003 no cotidiano escolar. História \& Ensino, Londrina, v. 21, n. 2, p. 283306, jul./dez. 2015.

DOURADO, L. F; OLIVEIRA, J. F. A qualidade da educação: perspectivas e desafios. Cad. Cedes, Campinas v. 29, n. 78, p. 201-215, maio/ago., 2009.

ESQUISSANI, R. S. S.; SOBRINHO, S. C. O desafio da função social docente diante das políticas educacionais em curso no Brasil. Jornal de Políticas Educacionais. v. 14, n. 17, p. 1-14, março, 2020. 
EUGENIO, B. G.; SANTANA, F. Relações étnico-raciais e o trabalho com a Lei 10.639/o3: análise de uma experiência com formação docente. Ensino \& Pesquisa, v.16, n. 1, p. 58-73, 2018.

GERHARDT, T. E.; SILVEIRA, D. T.; Orgs. Métodos de Pesquisa. Porto Alegre: Editora UFRGS, 2009.

GOMES, N. L. Diversidade étnico-racial, inclusão e equidade na educação brasileira: desafios, políticas e práticas. RBPAE, Goiânia, v. 27, n. 1, p. 109-121, jan./abr. 2011.

GIL, A. C. Como elaborar projetos de pesquisa. 6. ed. São Paulo: Atlas, 2019.

HENRIQUES, R.; CAVALLEIRO, E. Educação e Políticas Públicas Afirmativas: elementos da agenda do Ministério da Educação. In: SANTOS, S. A. (Org.). Ações Afirmativas e combate ao racismo nas Américas. Brasília: Ministério da Educação, Secretaria de Educação Continuada, Alfabetização e Diversidade, 2005.

JOHNSON, R. B.; ONWUEGBUZIE, A. J; TURNER, L. A. Journal of Mixed Methods Research, v. 1, n. 2, p. 112-133, 2007.

MARCONI, M. A.; LAKATOS, E. M. Fundamentos da metodologia científica. 6. ed. São Paulo: Atlas, 2009.

MARCONI, M. A.; LAKATOS, E. M. Técnicas de pesquisa: planejamento e execução de pesquisas, amostragens e técnicas de pesquisas, elaboração, análise e interpretação de dados. 8. ed. São Paulo: Atlas, 2018.

MUNANGA. K. Lei 10639/o3: depoimento. [São Paulo, fevereiro 2005] Entrevistador: Fábio de Castro. Disponível em:

<http://www.reportersocial.com.br/entrevista.asp?id=60>. Acesso: 25/02/2020.

OLIVEIRA, D. A. A política educacional brasileira: entre a eficiência e a inclusão democrática. Educação e Filosofia, Uberlândia, v. 28, n. especial, p. 225$243,2014$.

OLIVEIRA, D. A. Das políticas de governo a política de estado: reflexões sobre a atual agenda educacional brasileira. Educação \& Sociedade, Campinas, v. 32, n. 115, p. 323-337, abr./jun. 2011.

OLIVEIRA, C. L. Os professores em formação no LE campo: uma análise decolonial. @rquivo Brasileiro de Educação, Belo Horizonte, v. 6, n. 15, set./dez, 2018. 
PAULA, B. X.; GUIMARÃES, S. 10 anos da lei federal no 10.639/2003 e a formação de professores: uma leitura de pesquisas científicas. Educação Pesquisa. São Paulo, v. 40, n. 2 p.435-448, abr/jun. 2014.

PARO, V. H. Parem de preparar para o trabalho: Reflexões acerca dos efeitos do neoliberalismo sobre a gestão e o papel da escola básica. In: FERRETTI, C. J. et al. (orgs.) Trabalho, formação e currículo: para onde vai a escola. São Paulo: Xamã, 1999. p.101-120.

RIBEIRO, D. A Lei nº. 10. 639/03: limites e perspectivas para a Educação das Relações Étnico-Raciais. EDUCERE - XII Congresso Nacional de Educação. Formação de professores, complexidade e trabalho docente. PUCPR 26 a 29/10/2015.

SANTOS, R. A Lei n ${ }^{0}$ 10639/03: Entre práticas e políticas curriculares. História \& Ensino. Londrina, v. 16, n. 1, p. 41-59, 2010.

SANTOS, K. S. Políticas públicas educacionais no Brasil: tecendo fios. In: XXV Simpósio Brasileiro de Política e Administração da Educação/II CongressoIbero-Americano de Política e Administração da Educação, 2011, São Paulo. Cadernos ANPAE. São Paulo-SP: ANPAE, 2011.

SANTOS, É. A educação como direito social e a escola como espaço protetivo de direitos: uma análise à luz da legislação educacional brasileira. Educ. Pesqui., São Paulo, v. 45, p.1-15, 2019.

SILVA, W. S.; MARQUES, E. P. S. Educação e relações étnico-raciais: a Lei 10.639/03, a formação docente e o espaço escolar. Horizontes, v. 33, n. 2, p. 47-56, 2015.

SILVÉRIO, V. R.; RODRIGUES, T. C.; DOMINGUES, A. C. Diretrizes Curriculares e Plano Nacional de Implementação da lei no 10.639/03: balanço de implementação, desafios e perspectivas. In: Educação das Relações Raciais - Acão Educativa. Disponível em: <www.acaoeducativa.org > 10_anos_da_lei_10693_07_jul_2016>.Acesso em 26/04/2020.

SOUSA, S. Z. L. Avaliação da aprendizagem na legislação nacional: dos anos 1930 aos dias atuais. Estudos em Avaliação Educacional. São Paulo. v. 20. n. 44. Set./dez. p. 453-470, 2009.

SOUZA, J. V. A. Introdução à Sociologia da Educação. 2 ed. Belo Horizonte: Autêntica, 2009. 


\section{Sobre os autores}

Leandra Aparecida Mendes dos Santos Rodrigues: Possui graduação em Letras (Português/Inglês) pela Universidade Estadual de Goiás (2003). Pós-Graduação "LatoSensu" em Psicopedagogia pela Universidade Estadual de Goiás (2005). Atualmente é professor IV pela Secretaria da Educação de Goiás. Mestranda em Ensino Educação Básica no Instituto Federal de Educação, Ciência e Tecnologia Goiano Campus Urutaí. E-mail: leandra.aparecida@hotmail.com

Leida Corrêa da Silva: Possui graduação em Letras (Português/Inglês) pela Universidade Estadual de Goiás (2001) e Especialização em Literatura Brasileira pela Universidade Salgado de Oliveira (2004). Atualmente, é professora efetiva da Secretaria de Estado da Educação de Goiás. Mestranda em Ensino Educação Básica no Instituto Federal Goiano Campus Urutaí. E-mail: leida.silva@seduc.go.gov.br

Patrícia Gonçalves de Jesus: Possui graduação em Tecnologia em Alimentos pelo Instituto Federal Goiano - Campus Urutaí (2010), graduação em Pedagogia pela Faculdade de Ciências de Wenceslau Braz (2015), especialização em Docência do Ensino Superior pela Universidade Candido Mendes (2013), ensino-médio-segundo-grau pelo Colégio Estadual " Maria Paula Junqueira Uchôa" (2005) e aperfeiçoamento em Técnico em Sistemas de Informação pelo Instituto Federal Goiano - Campus Urutaí (2005). Atualmente é técnico administrativo do Instituto Federal Goiano - Campus Urutaí. Mestranda em Ensino Educação Básica no Instituto Federal Goiano Campus Urutaí. Email: patricia.goncalves@ifgoiano.edu.br

Cristiane Maria Ribeiro: Possui Graduação em Pedagogia pela Universidade Federal de Goiás (1995), Mestrado em Educação pela Universidade Federal de Uberlândia (2000) e Doutorado em Educação pela Universidade Federal de São Carlos (2005). Foi professora efetiva da Universidade Federal de Goiás e atualmente está vinculada ao Instituto Federal Goiano na condição de professora. Tem experiência na Educação Básica e em pesquisa principalmente os seguintes temas: Educação, Negros, Políticas Educacionais e História da Educação. É professora do quadro permanente do Programa de Pós Graduação em Educação Profissional e Tecnológica do Instituto Federal Goiano. E-mail: cristiane.maria@ifgoiano.edu.br 